\title{
Del autómata al personaje de animación: evolución de los sistemas de representación y reconocimiento del movimiento*
}

Recibido: 19/09/2019 | Revisado: 03/03/2020 | Aceptado: 17/03/2020

DOI: 10.17230/co-herencia.17.33.3

\author{
Jesús Alejandro Guzmán Ramírez** \\ jesusa.guzmanr@utadeo.edu.co \\ Diego Felipe Ríos Arce*** \\ diego.rios@utadeo.edu.co \\ Juan David Aristizábal Gómez**** \\ juand.aristizabal@utadeo.edu.co
}

Resumen A lo largo de la historia el ser humano ha sentido interés por el fenómeno del movimiento y su vínculo con la ilusión de vida; diferentes mecanismos y sistemas articulados se han construido con el fin de insuflar vida en seres inertes. El presente artículo reflexiona sobre la cualidad móvil del acto creador presente en diferentes campos socioculturales, desde el misticismo hasta los avances tecnológicos. Se parte del enigma del anima (alma), y su conexión con los creadores, denominados ejecutantes (constructor-operador, titiritero y animador) y sus creaciones, denominadas "avatares encarnados" (autómata, títere y personaje animado). Se analizan las relaciones de control-libertad, dependencia-independencia entre el ejecutante y su "avatar encarnado"; como también el grado de aceptación que tiene la audiencia al ver las creaciones reproducidas bajo el dispositivo diacrónico (máscara-pantalla). La transición del autómata al personaje animado constata la evolución de los sistemas de representación y reconocimiento del movimiento.

\section{Palabras clave:}

Anima, autómata, títere, personaje animado, avatar encarnado, ejecutante, máscara-pantalla.
El presente artículo está adscrito al proyecto del proyecto de investigación Procesos de integración al interior de las prácticas de animación derivadas de la generación de sistemas de artefactura en el diseño de movimiento.

Fase 2, Escuela de Diseño, Fotografía y Realización Audiovisual de la Universidad Jorge Tadeo Lozano, Bogotá-Colombia.

** Magíster en Diseño y 


\section{From the Automaton to the Animation Character: Evolution of Representation Systems and Recognition of Movement}

\begin{abstract}
Throughout history, humans have been interested in the phenomenon of movement and its connection to the illusion of life; different mechanisms and articulated systems have been built with the purpose of breathing life into inert beings. In this article, the movement quality of the creation act present in different sociocultural fields is reflected on in areas ranging from mysticism to technology. The starting point is the enigma of the anima (soul) and its connection to the creators-named performers (i.e., builder-operator, puppeteer, and animator) — and their creations-called "embodied avatars" (i.e., automaton, puppet, and animated character). The relationships of controlfreedom and dependence-independence between the performer and their "embodied avatar" are analyzed, as well as the degree of acceptance that the audience shows when watching the creations that are reproduced through the diachronic device (mask-screen). The automaton's transition toward the animated character proves the evolution of representation systems and the recognition of movement.
\end{abstract}

\section{Keywords:}

Anima, automaton, puppet, animated character, embodied avatar, performer, mask-screen.
Creación Interactiva y doctor en Diseño

y Creación de la

Universidad de Caldas. ORCID: 0000-0001-

$8249-2114$

**** Magíster en

Semiótica de la

Universidad Jorge

Tadeo Lozano.

Miembro de Asifa, capítulo Colombia.

Profesor asociado

de la Universidad

Jorge Tadeo Lozano,

Bogotá-Colombia.

***** Joven investiga-

dor de Colciencias

en el campo de la

innovación social

(2019-2020). Profe-

sional en Publicidad

y Diseño Gráfico de

la Universidad Jorge

Tadeo Lozano, Bogotá-

Colombia. ORCID:

0000-0001-6830-7197

Al instante fueron hechos los maniquies, los [muñecos] construidos de madera [...] No tenían ni ingenio ni sabiduría, ningún recuerdo de sus Constructores, de sus Formadores; andaban, caminaban sin objeto [...] ni sangre, ni humores, ni humedad, ni grasa; mejillas desecadas [eran] sus rostros; secos sus pies, sus manos; comprimida su carne. Por tanto [no había] ninguna sabiduría en sus cabezas, ante sus Constructores, sus Formadores, sus Procreadores, sus Animadores.

El Libro del Consejo (Popol Vuh $)^{1}$

¿Qué fuerzas sobrenaturales debe arrogarse el hombre para tener entre sus manos el don divino de simular la vida?, ‘acaso es su

1 El Popol-Vuh -Libro del Consejo en su traducción del quiché- es quizás el más antiguo relato recopilado del mundo mesoamericano de los mayas antes de la conquista de América. El Popol-Vuh narra la génesis del mundo maya y la conformación de su forma de vida como individuos vinculados a una cosmogonía nutrida de dioses, fenómenos y necesidades espirituales. La edición citada es la de Georges Raynaud, J. M. González de Mendoza y Miguel Ángel Asturias (2004, p. 12). 
maldición caer presa de su necesidad de creación debido a la insana osadía de ofrecer aliento de vida a materia inerte, o simplemente se trata de los rezagos de una superstición derivada de la fascinación con la caída sistemática de las deidades frente al arrollador peso de la ciencia y los avances tecnológicos? El presente artículo aborda la reflexión sobre la manera en que los humanos han percibido y dado significado trascendente al movimiento como evidencia de vida, desde aquel que se encuentra presente en la locomoción, así como el que se observa en otros seres y que han buscado insuflar no solo en entidades biológicas. Para entenderlo, se lo ha tratado de definir en las antiguas civilizaciones y dialectos, como, por ejemplo, el latín anima o el griego psique, por mencionar las definiciones más renombradas y cercanas al fenómeno de lo animado para la comprensión actual.

En las anteriores acepciones, se coincide en que el hombre relaciona la idea del "alma" con el movimiento y la posibilidad de que ciertos objetos la posean, por medio de diferentes prácticas, algunas ancestrales, que durante generaciones se convirtieron en expresiones culturales de carácter "totémico" o "tribal". Estas pretendían fusionar de manera "artificial" aspectos de orden espiritual con formas mecánicas móviles y construidas, determinando el fuero interno y autónomo del ser o del ente, hablando del "ser creado" y de la evidencia de su creador y cruzando de esta manera las nociones de ánima-movimiento-vida con las propiedades casi "mágicas" en el acto de animar (dar vida). Esta visión de la vida como un sistema "moviente" se deriva de la concepción humana de la "ideokinesis" (Sierra, 2015, pp. 55-57), aspecto que es inherente a cualquier elemento u objeto de la realidad y que consiste en la percepción del movimiento que posee cada objeto en sí mismo (Cholodenko, 2007, pp. 283-284; 2016, pp. 2-3; Pikkov, 2010, pp. 10-40). Dicho aspecto es ínsito en el ser humano y una evidencia de ello es como, para cualquier niño pequeño, un automóvil que se mueve se percibe más vital que un árbol que ante sus ojos parece inmóvil.

En este solapamiento de ideas y descubrimientos sobre las relaciones intrínsecas entre vida y movimiento, se busca indagar cómo desde coordenadas en apariencia opuestas como la espiritualidad, la ciencia, las narraciones ficcionales, los textos históricos, y los demás enfoques existentes, se proponen búsquedas permanentes 
para la creación de entes con capacidad de movimiento autónomo o aparentemente autónomo que incluso lleguen a dar la sensación o apariencia de "libre albedrío" o "espíritu". A partir de este punto de consenso se pretende ahondar en la motivación que hace que se valore la cualidad móvil como característica indivisible de la vida, relacionándola directamente con el "hacedor de imágenes", 2 figura que se vincula a roles históricos que han tenido la responsabilidad de crear el simulacro del movimiento humano en su debido momento.

Artesanos, ingenieros, mecánicos, artistas, titiriteros y, prácticamente desde mediados del siglo XIX, animadores, hacen uso de diferentes técnicas para dotar de vida a sus creaciones. De este modo, una y otra vez tratan de recrear a otros semejantes -casi vivientes- a los mismos seres que componen el mundo natural, "real", que se reconocen como una creación válida si se mueven de manera similar a la que se asocia con lo vivo. Es lo que Cholodenko (2007, 2009, 2016) define como lo "animático" a lo largo de su obra, pero que entra en el terreno de lo siniestro al poseer altos grados de similaridad, aunque nunca igualdad con los seres vivos (en especial con el humano), o no se diferencian lo suficiente como para poder concebirlos como claras representaciones "juguetes"- producto del intelecto humano, que si bien llegan a ser muy sofisticados, en sí mismos solo pueden hacer cosas muy básicas a los ojos de su creador (Lorenzo, 2013, p. 192).

Ejemplo ficcional de lo anterior, que incluso lleva el problema a escenarios éticos sobre la evolución no biológica de la especie humana, y que pone en duda las leyes de $\mathrm{Asimov}^{3}$ (Bueno y Peirano,

2 En términos generales, la idea del hacedor de imágenes se refiere al sujeto creador de esquemas de representación que impactan en una cultura y que permiten la apropiación de elementos simbólicos alrededor y dentro de estas producciones.

3 Desde sus primeros escritos alrededor del año de 1942 en textos como Runaround (1942), y posteriormente en las compilaciones hechas desde los años 50 hasta los 90, Asimov plantea la concepción de tres leyes iniciales que permitirían la convivencia entre autómatas y humanos para poder sobrepasar el síndrome de Frankenstein. Las tres leyes originales de Asimov son: (1) un robot no debe dañar a un ser humano o, por su inacción, dejar que un ser humano sufra daño; (2) un robot debe obedecer las órdenes que le son dadas por un ser humano, excepto si estas órdenes entran en conflicto con la primera ley, y (3) un robot debe proteger su propia existencia, hasta donde esta protección no entre en conflicto con la primera o la segunda ley. Sin embargo, Asimov en un proceso in extremis ético y moral incorpora una cuarta ley (ley Cero) que tiene prioridad sobre las demás leyes; en la novela Robots and Empire, resultado de la reflexión "ontológica" de androides 
2009, p. 315), es el caso de la tragedia de los replicantes nexus-6 en la novela de ciencia ficción Do Androids Dream of Electric Sheep? de Philip K. Dick (1968), adaptada al cine en Blade Runner por Ridley Scott (1982); seres que ya no solo se mueven como humanos, sino que lo hacen incluso mejor que sus creadores y que, en efecto, el índice de la terminación de su corta y trágica existencia es perder su capacidad de movimiento.

Este factor evidencia uno de los elementos característicos de la intervención del creador en sus creaciones, ya que al lograr actualmente la fabricación de entidades que pueden llegar a tener un carácter autónomo, independiente y con posibilidad de imitar procesos de pensamiento -inteligencia artificial-, siempre se asegura en dejar una salida, una "llave de seguridad" que le permite el control sobre el destino de su creación, aunque a primera vista se haya desvanecido en el artefacto del ejecutante mismo.

\section{En busca de la "mecánica del alma"}

Una cualidad presente en prácticamente todas las culturas es la necesidad de proyectar creencias animistas en sus mitos, subordinadas al terreno de lo espiritual; la observación de esa dimensión del mundo integra todo lo que no se comprende, pero que se desea controlar (Pikkov, 2010, p. 36). Esta cualidad adquiere significado en la palabra proveniente del latín anima, que traduce "aliento de vida", "principio vital" o "alma", y evidencia el carácter divino del acto de crear la ilusión de movimiento (Pikkov, 2010, p. 15).

Partiendo de lo anterior, tal como lo plantea Cholodenko (2007), en el animar, el animador muere en su estado previo y emerge como un nuevo individuo mediante su creación -relación temporal ser-objeto (Montoya, 2011, p. 73; Sanín, 2009, p. 61)-, en tanto que las unidades estáticas son vistas como imagen en movimiento por la audiencia a la que va dirigida. Esta imagen en movimiento es el artefacto audiovisual que a su vez ha extraído elementos de su creador, recibiendo la delegación de transmitir la esencia (anima-psique) del

de muy alto nivel como R. Daneel Olivaw, el autor menciona: "Un robot no hará daño a la humanidad o, por inacción, permitir que la humanidad sufra daño" (1985, p. 372). 
animador ya transparentado por medio de la máscara-pantalla que es el dispositivo diacrónico. Esto permite que la audiencia se vea a sí misma reflejada y expuesta en su propia entonación, en la cual el movimiento ofrece la verosimilitud necesaria para que deje de lado el artificio de "la ilusión del movimiento" y de este modo se lleve a cabo la apropiación del artefacto audiovisual como representante de la propia realidad (Pikkov, 2010, pp. 39-56).

Evidencia de esto se da ya en el Renacimiento, una época de descubrimientos mezclados con misticismo en la que sobresale Leonardo da Vinci, quien planteaba que el poder de "animar" es divino y pertenece a lo espiritual, y tal don no puede ser impuesto sobre objetos inanimados de la misma manera que se logra en el cuerpo humano; entonces, para que el hombre pueda imitar el acto de dar vida debe hacer uso del mundo físico por intermedio de palancas, ejes y fuerza mecánica. La visión de Leonardo sobre la separación entre las categorías divinas y humanas en la idea de generar movimiento se expresa en la siguiente cita:

La fuerza no es otra cosa que una virtud espiritual, una potencia invisible, que crean e infunden con una fuerza accidental los cuerpos sensibles a los insensibles, dando a estos últimos cuerpos apariencia de vida; y esta vida es una acción maravillosa (citado por Taddei, 2010, p. 23).

En este planteamiento de Da Vinci se recrean los más profundos temores y deseos del ser humano: entender el universo como un sistema que puede generar reacciones anímicas, como lo manifiesta Cholodenko. Así mismo, comprender el misterio detrás de la posibilidad de crear movimiento, vida, en un acto de rebeldía profunda, hace que sea imposible no verse afectado por el terror a las consecuencias de un ciclo que repetiría su desafío, pero ahora desde su propia creación (Bueno y Peirano, 2009, p. 314). Dicho temor es superado, eso sí, por la curiosidad y la necesidad de entender y apropiarse de las complejidades del mundo circundante, como si se tratara de una nueva oportunidad de nacer o de proyectar esa insatisfacción en un ser "hecho a la medida", proceso que se retrata en las piezas animadas The Second Renaissance, partes I y II (Maeda, 2003), cortos pertenecientes a la película The Animatrix (Chung et al., 2003). 
El nexo entre anima y psique no solo vincula lo espiritual, sino también lo mental, y permea de manera transversal todas las actividades relacionadas con el concepto de vida (movimiento) y de recreación de la vida (no muerte, animación, re-animación, presentación, re-presentación), lo que replantea el concepto eminentemente mecánico-biológico de lo cinemático mediante lo que Cholodenko define como animático (2007, 2009, 2016), para enlazar el movimiento a la esencia de todas las cosas. De manera similar, Charles Solomon (1987, p. 10) recuerda que una de las premisas básicas para el desarrollo de procesos animados es el hecho de que la ilusión de movimiento que se presenta es creada, y no el registro de una acción ya ocurrida, lo que significa que el verdadero sentido de animar reside en la construcción y el control sobre lo que va a ser animado, y no en la simple evidencia de un movimiento en sí.

Como lo cita Taddei (2010, p. 12), innumerables han sido los acercamientos que desde épocas pretéritas los hombres y sus dioses han tenido en la creación de entes autómatas de todo tipo. Qué tanto pertenece a la ciencia y qué tanto a la mitología no es del todo claro. Esa dualidad se presenta en el personaje de Bubo, un ingenio mecánico de origen divino que debe ayudar a Perseo en su misión titánica de derrotar al Kraken, secuencia que es abordada en el clásico del cine Clash of the Titans (Davis, 1981). Además de los griegos y de los árabes, ${ }^{4}$ también las culturas contemporáneas se fascinan con "seres" que, si bien derivan su origen de lo científico, se presentan igual de mágicos ante el espectador, como se muestra en el cortometraje francés El hotel eléctrico (De Chomon, 1908), donde el mobiliario y los artefactos automatizados se comportan de manera similar a los encantados sirvientes del palacio de La bella y la bestia (Trousdale y Wise, 1991).

Otro referente que plantea el misticismo y el carácter mágico de crear movimiento se presenta en la película Hugo (Scorsese, 2011), donde el huérfano, Hugo Cabret, trata de reparar un viejo autómata capaz de escribir, el cual posee como pieza vital para

4 Era común entre los griegos y los árabes la construcción de tháumatas o prodigios mecánicos a manera de juguetes ingeniosos cuya labor principal era el entretenimiento, y que le otorgaban estatus a su poseedor. 
su funcionamiento una llave en forma de corazón. El filme es un homenaje a Georges Méliès, uno de los primeros cineastas. Lo mágico encuentra una ruta de representación por medio del acto, el escenario, los artefactos, el cine y la imagen en movimiento que dejan perplejos y anonadados a los espectadores. Lorenzo (2013, p. 191) añade que el autómata, al ser reparado, muestra su don especial; en lugar de escribir, puede dibujar, lo que lleva a especular que si el androide hubiese dibujado otro diseño, ligeramente diferente al anterior, entonces el autómata sería una máquina cinematográfica avanzada: sería un animador.

Además de la magia, en Hugo (Scorsese, 2011) se equipara al ser humano con el "ente" máquina, como lo describe el personaje de Méliès: "[...] una vez inventé un autómata funcional, él era un tesoro particular, puse mi corazón y alma en él”, o como se menciona también en la conversación entre Hugo e Isabelle, en la que Hugo considera el mundo como una enorme máquina y hace alusión al "propósito" de la vida:

Todo tiene un propósito, incluso las máquinas; los relojes dan la hora, los trenes nos transportan, hacen lo que deben hacer, como monsieur Labisse. Por eso las máquinas averiadas me ponen tan triste, no hacen lo que deben hacer. Tal vez sea igual con las personas, si pierdes tu propósito, estás averiado (Scorsese, 2011).

Las anteriores referencias se pueden ver en simbiosis en la enajenada mente artificial de la diva de ópera del corto Magnetic Rose (Morimoto, 1995), donde se recrea un ambiente surreal de recuerdos y fantasías implantados en una máquina que como venus atrapamoscas perpetúa su existencia y necesidad de atención atrayendo desventurados socorristas a su interior. Es aquí donde el control del hombre sobre una fuerza como la electricidad es igual de potente a la magia ancestral, que a su vez de manera sutil aún se mezclaba con los avances tecnológicos en los inicios de la era moderna y que toma forma en representaciones animadas.

\section{El ejecutante y su reflejo en el ser creado}

En este afán de comprender y controlar surge el "ser" detrás de la mecánica del movimiento; el "sujeto" como fuerza motora o 
mecánica y a la vez sensible, no en sí mismo, a manera de energía, sino como engendrador de los sistemas y funcionamientos que pueden dar "vida" a los cuerpos insensibles, como los definía Leonardo. La ciencia ofrece así un gran campo de posibilidades que convierten el estudio de la neumática y la hidráulica en una forma de pensamiento y creación. El generador de vida a partir de la mecánica es entonces designado como ingeniero, que es a la vez constructor e inventor y, tal como Julien Offray de La Mettrie en su tratado El hombre máquina (L'Homme Machine, 1748), concibe a la naturaleza como un "ente" racional, inteligible y asimilable desde la ciencia.

Partiendo de esta percepción, se asume que se puede escalar la idea de ver al ser humano como una máquina que puede ser reproducible y que, pese a la complejidad de dicha creación -que tiende a volver inviable tal empresa-, la ingeniería podría resolver el enigma con el paso del tiempo. ${ }^{5}$ La construcción de elementos que parten de la naturaleza permite percibir los objetos dentro del marco de la realidad (Wagensberg, 2004, p. 19), sus semejanzas y cualidades son trasladadas por el constructor imitando los valores determinados por la naturaleza, que mediante mecanismos se apropia de su inteligibilidad por lo menos en la ejecución (Taddei, 2010, p. 12).

Es así como se comienzan a desarrollar, a partir del conocimiento de la física, las formas que se requieren ensamblar para determinar los comportamientos de los objetos a ser manipulados, mediante poleas y mecanismos que diluyen su propia forma tras de sí, y que se convierten en un reemplazo de la imagen del ejecutante, en una especie de mecanismo que deja entrever la inteligencia del creador, pero que nunca deja que se manifieste explícitamente. Lo cual permite que, como lo manifiesta Weihe (citado por Buchan, 2006, p. 41), se logre dar animosidad por medio de la evidente falta de vida en

5 Ingenieros como Jacques de Vaucanson realizaron un enorme progreso durante el siglo XVIII en el desarrollo de mecanismos que simulaban o imitaban los movimientos de diferentes tipos de seres. Sin embargo, este particular inventor, considerado el rival de Prometeo, tuvo como su logro más extraordinario, aparte de un pato mecánico que poseía procesos digestivos visibles, a un flautista prodigioso que podía entonar de manera precisa cerca de veinte melodías a la par que tocaba un pequeño tambor. Este tipo de artificios plagaban el imaginario europeo de rumores que lindaban entre lo científico y lo místico, siendo objeto a veces incluso de persecución religiosa por parte de la Iglesia al no estar seguros de no tener involucrados en los procesos de desarrollo las artes oscuras (Bueno y Peirano, 2009, pp. 47-55). 
los mecanismos en sí mismos. En esta suerte de "tendones y músculos" mecánicos que simulan los cuerpos orgánicos, surge para el ojo no conocedor el sentido automatos ${ }^{6}$ del ser mecánico (Taddei, 2010, p. 12), que simula funciones en apariencia idénticas a la del "ente" natural a replicar sin importar el tipo de animal o artificio del mundo que imita, pero que al acercarse a las formas del hombre y sus comportamientos se hace más importante el cómo se ve al cómo se hizo. De allí se deriva una nueva denominación que en el mundo contemporáneo reemplaza a la de autómata, como una categoría exclusiva a los propios ojos humanos: el androide (Bueno y Peirano, 2009, p. 41).

En este punto se identifica el material propio utilizado para la conformación del cuerpo al que se le otorga "alma", y que es el sentido en el que Leonardo enfatiza la diferencia y el temor con las acciones del hombre al intentar insuflar vida en un ser inerte, o que se reversan buscando una ampliación de la capacidad humana mediante implantes tecnológicos -ciborg-, como se presenta en el manga y en la posterior serie de animaciones Ghost in the Shell (Oshii, 1995), cuya versión en live-action fue dirigida por Rupert Sanders (2017).

De igual modo, otras mitologías antiguas refieren la creación de seres surgidos de elementos inanimados -madera, barro, etcétera-, que en algunos casos tienen emociones y en otros no, como sucede en los relatos mayas cuando describen a los hombres de madera que terminan siendo destruidos por sus creadores al no levantar alabanzas y reconocerlos como sus señores.

Por su parte, los judíos tienen en su haber a la figura mítica del Golem, un ser que surge alrededor del siglo XVI, creado aparentemente por el rabino Judah Loew ben Bezalel, quien lo creó a partir del barro y para controlarlo utilizó fórmulas matemáticas y palabras extraídas de la cábala (Meyrink, 1995, p. 12). En su novela El Golem (Der Golem, 1995 [1915]), Meyrink ${ }^{8}$ describe que este "homúnculo" (Chinchilla,

6 Automatos proviene del griego y significa "espontáneo", que es de donde surge el término autómata, es decir, un mecanismo ejecutante de mímesis que supone espontaneidad para el espectador.

7 Vocablo derivado del griego que significa "forma de hombre". En esencia es una categoría independiente que se le asigna a los autómatas con apariencia humana masculina; en el caso de las mujeres se le denomina "ginoide".

8 Gustav Meyrink escribió su novela en 1915, la cual fue sumamente popular en los cinco años siguientes. En 1920 Paul Wegener estrenó su película Der Golem, wie er in die Welt 
2001, p. 13) es animado solo por la mágica palabra que recreaba el "verbo divino", no poseía alma, y cada noche debía retirársele el papel que la contenía para evitar que se saliera de control.

\section{Imagen 1}

El Golem. Perdición de su amo

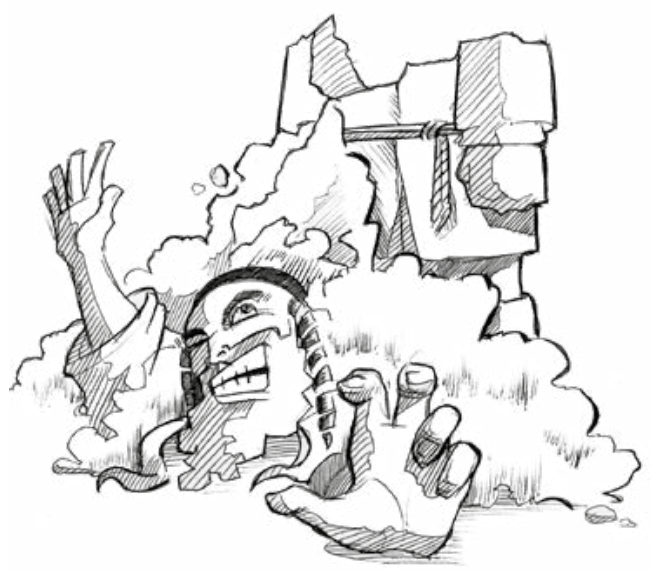

Fuente: Elaboración nuestra.

Chinchilla (2001, p. 14) plantea que en medio de ese recorrido místico de la cábala, en el que el hombre concibe su propio doble para expiar su culpa, se construye un ser excepcional lleno de poder con la capacidad de crear o destruir su propio universo (imagen 1), y que en las actuales corrientes posmodernas puede equipararse, por medio de la tecnología, con la figura del robot, que incluso puede ser de origen divino o extraterrestre, como se observa en el coloso de metal The Iron Giant (Bird, 1999).

kam, adaptación de la ya afamada obra literaria. En 1968 el escritor Philip K. Dick escribió su novela ¿Sueñan los androides con ovejas eléctricas? que inspiró la película de culto de Ridley Scott, Blade Runner (1986), que recrea de manera contemporánea el dramático destino de darle vida artificial a seres con mayor fuerza, inteligencia y capacidad que la del propio hombre, terminando en un final fatídico casi siempre para el ser creado, debido a la fanática necesidad del ser humano de exterminar a un posible reemplazo, así sea creado por su propia mano, una vez se sale de control. 
La recreación artificial del propio ser ${ }^{9}$ es relacionada por diferentes autores con la fascinación atávica por el reflejo humano, su sombra o el miedo a la muerte. Bueno y Peirano (2009, p. 227) se refieren a dicha intriga cultural como la necesidad del ser humano de tener un seguro ante su inminente destrucción; incluso plantean la visión del alma como el primer doble del cuerpo mismo en un irreverente acto de permanencia espiritual.

Lo anterior se refleja en la novela de David Brin (2002) Kiln People, en la cual la figura del Golem se expone en forma de duplicados corpóreos de humanos arquetípicos. Los "Archies" son personas reales que depositan su memoria en cuerpos artificiales de barro denominados "dittos", copias desechables compuestas de pseudoalma cuya duración es limitada, quienes cumplen funciones que no desea hacer el propietario. Partiendo de esto, se puede evidenciar cómo la creación empieza a tener aspectos similares al creador, con segmentos de su alma o vida que lo hacen cuestionar su propósito. Esto se observa en la serie de los robots ${ }^{10}$ de Asimov, donde el androide R. Daneel Olivaw se hace preguntas sobre su existencia, acerca de su finalidad y su vínculo con la humanidad.

El creador se vuelve dependiente de su obra, así como la obra es coaccionada por su creador. Esto hace que la creación se cuestione a sí misma al verse prescindible, y detona la rebelión de la obra frente a su creador buscando su permanencia. Este caso se presenta en la novela Kiln People con el "ditto verde" del detective Albert Morris, cuando se convierte en un "Frankie", una copia imperfecta que se declara independiente de su creador. Debido al temor de la creación a desvanecerse y corroerse, esta se rebela con el deseo de tener las mismas posibilidades de trascendencia.

En sentido extenso, el hombre se ha inclinado desde hace ya varios siglos a tratar de develar los resultados de la construcción de un

9 El concepto del Doppelgänger o "doble" suscita una enorme cantidad de relatos e imaginería popular en muchas culturas alrededor del mundo. En ocasiones este desplazamiento del individuo es causado de manera intencional y en otras es una construcción espontánea de un mundo incomprensible para el ser humano. Pero en cualquiera de ellas, el duplicado busca tarde que temprano reemplazar al original y utiliza cualquier tipo de artimaña para eliminarlo.

10 La serie de los robots comprende las siguientes novelas: Yo, robot (1950), Bóvedas de acero (1954), El sol desnudo (1957), Los robots del amanecer (1983) y Robots e imperio (1985). 
"reflejo", tanto en procedimiento como en forma y comportamiento, encontrando en la literatura algunos de sus más grandes hitos. Que van desde las oscuras noches de las veladas que Mary Shelley tuvo como base germinal para su criatura Frankenstein (Frankenstein or, The modern Prometheus, 2015 [1818]), que sienta una clara connotación siniestra acerca de la construcción de una forma de vida artificial y la retaliación de la creación hacia su creador, hasta los brillantes momentos en que Andrew Martin, concebido por Asimov (The Bicentennial Man, 1976) para redimir el vínculo entre los humanos y sus "herederos tecnológicos", muestra a un hombre que posee una desarrollada inquietud para crear algún tipo de artificio que le haga "compañía” en su solitario viaje emocional.

Larga es la lista de intentos (imagen 2, infra) por encontrar un "igual" a la vez perfeccionado, como se presenta la imperturbable Olimpia (Hoffmann, 1816) y que al igual que la notable Hadaly (De l'Isle-Adam, 1998 [1886]) deliciosamente construida desde cualquier punto de vista, fueron la desgracia y la locura de sus amantes, pasando por los robots ${ }^{11}$ de la R. U. R. Robots Universales Rossum de Karel Čapek (2017 [1920]) inmaculados en su construcción y carentes de cualquier sentido de existencia y, por lo tanto, según el autor, de error. Hasta encontrar el concepto de hibridación entre mente -o espíritu- y máquina que se inicia con la desgraciada Hel atrapada dentro de la fría carcasa de Parodia que habita en Metrópolis (Lang, 1927), que posteriormente será utilizada como sistema de castigo a la atribulada ciudad y sus nefastos dirigentes.

Décadas después, autores como Rudy Rucker (1988) retoman la tragedia de Shelley en una visión biopunk $k^{12}$ de la que surge el término meatbots, para representar a unos seres biorobóticos que lograron encontrar la forma de insertar software dentro de organismos humanos

11 El término robot se le atribuye al maestro Čapek, al buscar un concepto que definiera a su creación en la obra teatral que estaba desarrollando. La traducción de dicha acepción deriva del checo robota y significa "trabajo" o "prestación personal" (Bueno y Peirano, 2009, p. 297).

12 El concepto del biopunk es un subgénero literario del ciberpunk muy popular en los años 80. Su énfasis hacia la hibridación orgánico-digital evidenciaba la inquietud hacia los desarrollos en la ciencia genética que apenas daban sus primeros pasos y el inmenso mundo que se empezaba a abrir con el surgimiento de la Internet, encontrando elementos en común en los conceptos base de transmisión de información, autorreproducción y organicidad. 
con el fin de autorreproducirse y lograr por fin la independencia del yugo orgánico.

Cerrando el ciclo se encuentra el contemporáneo Jake Sully, en Avatar (Cameron, 2009) que resume tanto temores como posibilidades esperanzadoras en un mundo en conflicto que pugna entre la tecnología devoradora y la posibilidad de proyectar hacia un desarrollo biotecnológico todos los pensamientos, razón y sentimientos humanos. Sully puede ser controlado como una máquina sin alma propia, lo que, en lugar de rebelarse, le permite ser un vehículo potenciado del humano, buscando quizás la respuesta a la rebeldía natural de la "obra", que es la de ser una con su creador.

\section{Imagen 2}

Panteón del Autómatos. Galería de creaciones humanas

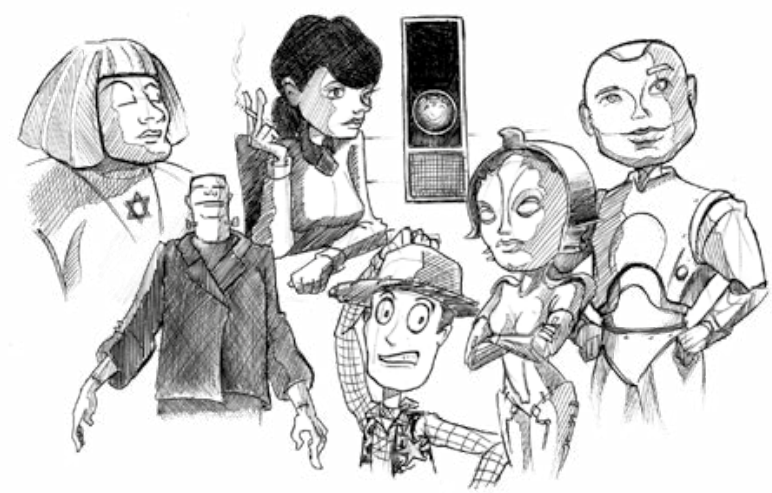

Fuente: Elaboración nuestra.

\section{El lado oscuro de la creación animada}

El ejecutante no se arriesga a dar forma a una copia de sí mismo sin haber tenido primero un entendimiento de la mecánica cósmica y de la manera en que podía comprender el devenir del mundo circundante. En su afán de "orden" se construyeron astrolabios, relojes de constelaciones, relojes planetarios, relojes con autómatas y un sinnúmero de artificios mecánicos que calculadamente fueron dando al hombre comprensión de los ciclos del tiempo y la influencia de este sobre los diferentes fenómenos naturales. 
Este principio relacional lo describe Wagensberg (2004, p. 19) en el libro La rebelión de las formas, al plantear que la realidad del mundo se compone esencialmente de objetos y fenómenos. Mientras los primeros determinan y son determinados por el espacio, es decir, lo que se percibe como entorno, y poseen características formales que aportan información al sujeto, los segundos, por su parte, se encuentran vinculados al concepto del tiempo y referencian los cambios que sufre un objeto. Al iniciarse el tiempo, la realidad y sus objetos comienzan a transformarse y expandirse, con el consiguiente despliegue temporal de las cosas. Los ejercicios derivados de la medición del tiempo y el movimiento de las cosas se convierten en un factor determinante para llegar a poseer la sensación de controlar lo incontrolable y medir los fenómenos que impactan sobre los objetos del mundo (imagen 3).

\section{Imagen 3}

Máquina antigua. Representación de la aplicación neumática e hidráulica

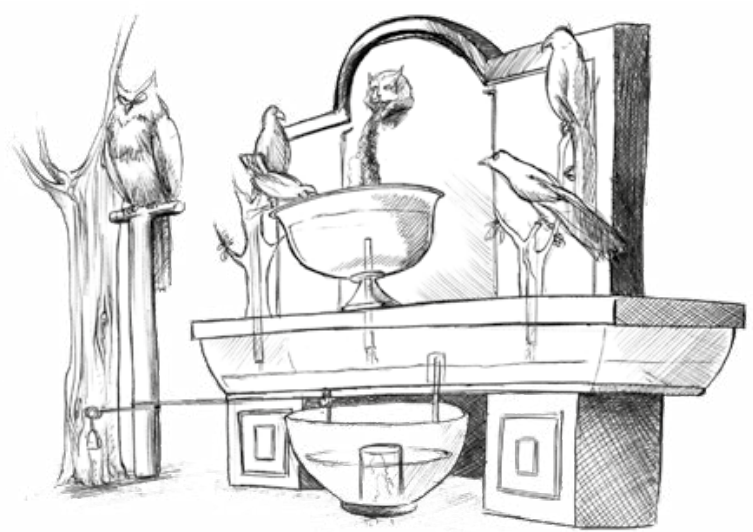

Fuente: Elaboración nuestra.

La laboriosa acción de comprender el fenómeno del movimiento debe entonces ser seguida por la necesidad de construir de forma directa los mecanismos para recrearlo -capacidad de entendimientoEsta ejecución práctica lleva al ejecutante a desarrollar todo tipo de artificios -tornillos, poleas, palancas, etcétera- y a someterlos a un sinnúmero de simulaciones recopiladas a lo largo de generaciones 
de ensayo y estudio progresivo. De nuevo el entendimiento de la forma de construcción y uso de máquinas simples y compuestas (Taddei, 2010, pp. 22-54) deriva en la generación de mecanismos que finalmente se convierten en el "sistema muscular" de los autómatas a lo largo de la historia y son a su vez las refinadas extensiones que usan los titiriteros o maquinistas para llenar de gracia los movimientos de las creaciones (Weihe, citado por Buchan, 2006, p. 40).

La generación de mecanismos conduce adicionalmente a la búsqueda de la representación del movimiento no solo desde lo mecánico, sino que se mezcla con el estudio de las percepciones y la emulación de la cinética por medio de artilugios como el taumatropo, el fenakitoscopio, el zootropo, o el praxinoscopio, entre otros, que aprovechando la percepción ojo-cerebral humana, permitieron explotar una nueva forma de apropiación del estudio de la fenomenología visual, en este caso de la luz sincronizada con la fisiología ocular, diseccionado el proceso a la mejor manera de Rotwang o Victor Frankenstein (Arce, Sánchez, \& Velásquez, 2013, pp. 42-62). Este tipo de ingeniero o inventor ya no se atribuye tanto el carácter divino como sí el de prestidigitador o mago (Pikkov, 2010, pp. 26-33), tal como fueron considerados Georges Méliès con sus procesos de experimentación cinematográfica, Athanasius Kircher al aprovechar la linterna mágica en sus presentaciones, Charles-Émile Reynaud al desarrollar su teatro óptico o el mismo Thomas Alva Edison, que no solo tuvo aportes importantes en el desarrollo del cine, sino que también desarrolló una patente de marioneta parlante y móvil en su afán creativo de darle vida a objetos inanimados.

Al igual que un mecanismo de reloj elaborado con extrema finura, cuyo deleite se encuentra en la detallada elaboración de sus componentes y la satisfacción del conjunto que representa perfectamente la apropiación del concepto de tiempo en un artefacto hecho por manos humanas, se parte de que la fascinación por el desarrollo de autómatas es lograr la mímesis perfecta de los seres que se replican (Pikkov, 2010, pp. 16-21), y encontrando su mayor deleite en lograr imitar o simular sentimientos humanos de manera fidedigna -androides o ginoides-. Este aspecto que en apariencia debería ser el culmen de los logros científicos y técnicos de la humanidad conduce 
a un complejo campo definido por autores como Ernst Jentsch ${ }^{13} \mathrm{O}$ Sigmund Freud como "lo siniestro" -unheimlich-, relacionado con la incertidumbre que produce en el humano el no poder diferenciar las conductas de un objeto inanimado de uno animado, o con el desasosiego que genera en el espíritu la duda sobre la vitalidad de un ser (Bueno y Peirano, 2009, pp. 209-210).

Además de los escritos de E. T. A. Hoffman que sirvieron como precedente para los estudios de Jentsch y Freud, hay una enorme cantidad de experiencias entre el siglo XIII y XVI que muestran lo que fue definido como "el complejo de Frankenstein", que es "el temor del hombre a que la máquina pudiera rebelarse contra su creador y, lo que es peor, que llegase a suplantarlo" (Bueno y Peirano, 2009, p. 314). Respecto al anterior temor, se puede citar un caso vinculado a Alberto Magno, quien construyó un sirviente mecánico excepcional, además de acuñar el término androide. ${ }^{14}$ Posteriormente, y a causa de una emoción de fobia frente a este artilugio mecánico, su discípulo Tomás de Aquino destruyó aquel artefacto sin dejar huella de su creación (Taddei, 2010, p. 15).

La conducta humana detectada en estos procesos de aversión hacia lo desconocido toma forma contemporánea en el texto de Masahiro Mori The Uncanny Valley ${ }^{15}$ (1970, pp. 33-35) quien lo contextualiza en relación directa con la robótica y su interacción con los seres humanos. Mori plantea una curva empática progresiva hacia los robots que evolucionan constantemente hacia una

13 Ernst Jentsch escribió en 1906 un ensayo titulado Zur Psychologie des Umheimlichen acerca de los temores de los seres humanos frente a lo que no les es conocido. Freud toma dichos conceptos para su ensayo The Uncanny (1919) donde no solo recopila los trabajos de Jentsch, sino que realiza un recorrido que evidencia la ambigua definición de lo siniestro en el sentido humano y que contrapone lo íntimo y conocido con lo oculto y lo bizarro. El concepto determinado por los autores se traduce de muchas maneras, entre ellas lo siniestro, lo inquietante o lo misterioso, todas ellas acepciones de lo perturbador que es para el ser humano la naturaleza mimética de un ser que se parezca a él.

14 Si bien Alberto Magno fue el primero en acuñar el concepto de androide alrededor del siglo XII, su primera referencia literaria se encuentra en el texto La eva futura (L'Ève Future) de Villiers de l'Isle-Adam (1886).

15 El valle misterioso planteado por Masahiro Mori ha sido fuente de estudios en el área de la animación, debido a la incidencia que tiene la mímesis de personajes 3D con la respuesta positiva del público. Dicha teoría ha sido evaluada por productoras como Pixar o Blizzard y plantean la necesidad de lograr algún tipo de distanciamiento de la realidad para no generar rechazo generalizado a sus producciones. 
apariencia humana, pero repentinamente un grado de mímesis demasiado alta genera completa aversión hacia dicho ente, a menos que dicha semejanza sea perfecta. Películas como Beowulf (Zemeckis, 2007), Final Fantasy VII: Advent Children (Nomura \& Nozue, 2005), o las cinemáticas de Diablo III: Reaper of Souls (Carpenter, 2012), entre otras tantas, se manifiestan entre los límites de este llamado "valle misterioso" y llegan incluso a generar sensaciones ambivalentes en la audiencia sobre la empatía que despiertan, debido a su grado de realismo y similitud con el mundo y sus fenómenos (Lorenzo, 2013, p. 192).

Dicha teoría se contrapone a posturas tecnófilas como las planteadas por el autor Marvin Minsky a lo largo de su obra y defienden la integración o asimilación de los humanos y la tecnología. En dicho sentido, en su libro The Emotion Machine (2006, pp. 10 110) Minsky explica extensamente las complejas estructuras que se van construyendo de manera progresiva a lo largo de la crianza y que se consolidan posteriormente como sistemas de respuestas parametrizadas para interactuar con otras personas. En dicho sentido expone que se forman "arquitecturas emocionales" que pueden llegar a ser utilizadas como interfaces de relación humano-máquina. Este tipo de respuesta se puede evidenciar en escritos como Satisfaction Guaranteed ${ }^{16}$ de Isaac Asimov (2001 [1951]), texto en el que se deja ver cómo una prueba de campo de un androide-sirviente llamado Tony afecta emocionalmente a una esposa solitaria hasta el punto de generar confusos sentimientos empáticos por parte de la mujer.

\section{De titiriteros a animadores}

Progresivamente, la creciente respuesta al desarrollo de las creaciones se enfoca no en lograr emociones reales en los autómatas creados, sino en simular las mismas hasta tal punto que los seres humanos respondan de manera no solo positiva sino recíproca con respecto a la tecnología. Ya sea mediante elaborados detalles, como los

16 Este mismo concepto es abordado en la película Inteligencia artificial (Spielberg, 2001), cuya base se remite al relato de Brian Aldiss, Los superjuguetes duran todo el verano (Supertoys Last All Summer Long and Other Stories of Future Time, 1969) que muestra la relación empática humanos-máquinas y genera cuestionamientos derivados de la "construcción" de emociones de cara al surgimiento espontáneo de estas. 
logrados por El flautista de Jacques Vaucanson (1737) y sus melodiosas interpretaciones que recibieron la aclamación de los espectadores franceses, hasta representaciones más actuales como las presentes en el filme Her (Jonze, 2013), en las que un hombre despechado encarnado en Theodore Twombly construye una relación afectuosa y progresiva con un sistema interactivo diseñado para servir de apoyo y compañía, evidencian que el ser humano ha logrado sincronizar -al menos idealmente- aspectos que de entrada parecen divergentes y difíciles de ensamblar sin la precisión cronométrica de un reloj, mostrando un camino para que el humano se mejore a sí mismo y sus capacidades, tal como lo citan Arce et al. (2013):

[...] poder ver y escuchar lo que está fuera de nuestro alcance y romper tantas otras limitaciones físicas se manifiestan en todas las culturas a lo largo y ancho del mundo; así mismo son prolíficas las formas como éstas se solucionan, en tales relatos, a través de la magia, la tecnología o la intervención divina (2013, p. 54).

Pikkov, en su libro Animasophy (2010) y Richard Weihe (citado por Buchan et al., 2006) plantean sendos aspectos derivados de la incursión de los inventores en el desarrollo de marionetas que le permiten al público presenciar, en tiempo real, movimientos de objetos que en otras circunstancias encontraría como inanimados, y que son completamente controlados por el ejecutante. Aparece entonces el titiritero como intérprete de la atávica tradición de poseer el conocimiento y los instrumentos para ejecutar una acción sobre sus creaciones, retomando el vínculo con categorías de carácter divino. Se visualiza entonces a las marionetas como figuras totémicas que permiten expresar la omnipotencia de los dioses y su capacidad de intervenir sobre la humanidad.

El personaje-creado, personaje-controlado y personaje-vivo se ve expresado en las raíces chamánicas y totémicas. Estos sistemas de creencias y prácticas involucran un vínculo con lo natural que permite que el "ser" trascienda y sobrepase las barreras de lo "autorizado". El ser humano tiene "el derecho a no obedecer los estatutos del mundo autorizado, el derecho a la imaginación infinita, el derecho a la fantasía y la magia, el derecho a la autocreación, el auto-desarrollo, el Ser por uno mismo" (Páramo, James y Jiménez, 2004, p. 13). 
En esa misma línea, Ed Hooks (2017) afirma que la actuación, como también el acto de dar vida a objetos inanimados, tiene sus orígenes en el chamanismo (p. 109). El chamán es una persona que ingresa a un estado alterado de conciencia, actuando como puente entre universos paralelos, parecido a un artista o actor que guía a los espectadores a una dimensión entre la vida y la muerte (Giesen \& Khan, 2018, pp. 26-27). El titiritero, al igual que un chamán, invoca el espíritu animado sobre marionetas totémicas para trascender su realidad. En este punto, el hilo de carácter chamánico es la mediación del titiritero expuesta por medio de la técnica sobre los personajes totémicos. Giesen y Khan (2018) mencionan que para un chamán todo posee vida, incluso una piedra, y eso también es cierto para el animador (p. 26).

Lo chamánico también se ve reflejado en el término doll/puppet con el cual Lotman (1980) relaciona lo lúdico de una muñeca/ marioneta con la creación de un nuevo mundo en el cual el jugador duplica su vida (citado por Thibault, 2016, p. 305). Durante el juego una muñeca/marioneta es un actor que puede representar varios personajes, desde humanos, animales y objetos, hasta máquinas, ya que la muñeca/marioneta funciona como un lienzo en el que se proyecta la imaginación del usuario (Thibault, 2016, pp. 304-305). Lotman añade que si el actor interpreta el papel de una persona, la muñeca/marioneta interpreta el papel del actor, lo que la convierte en la imagen de otra imagen (citado por Thibault, 2016, p. 304).

Este aspecto de misticismo que busca mantener en los espectadores una sensación de vida en las propias marionetas como seres independientes del titiritero, permite progresivamente que se repita de nuevo el desvanecimiento del ejecutante, en este caso ya no detrás del mecanismo, sino oculto tras el marco del escenario de visualización o de la pantalla de proyección. Quienes buscan representar movimiento por medio de marionetas se convierten entonces en el último eslabón en la extensa tradición del reto de la construcción de mecanismos de movimiento ya explorados en los autómatas (Pikkov, 2010, pp. 14-38).

Por otro lado, de la exploración mecánica de secuencias de imágenes proyectadas a través de rayos de luz, surge también otro tipo de ejecutante, igual de interesado en las problemáticas de representar 
la idea de movimiento y poder transmitir anima por medio de sus creaciones. A finales del siglo XIX se puede localizar la figura del animador como generador de vida a partir de secuencias fijas para llegar a una idea de movimiento. En este sentido, no se trata solo del proceso mecánico del construir el trazo fotograma a fotograma, sino de las intencionalidades subyacentes en este proceso que se equipara a la búsqueda de mímesis de emociones en los autómatas, lo que lleva a la animación a un estado de representación y manipulación no solo de la forma, sino de la idea de "realidad" con todas sus facetas; aspectos que resalta Norman McLaren: "La animación no es el arte de los dibujos que se mueven sino el arte de los movimientos que son dibujados; lo que sucede entre cada cuadro es mucho más importante que lo que sucede en el cuadro mismo" (citado por Solomon, 1987, p. 11).

Los animadores son titiriteros invisibles, cuyas manos son herramientas que se prestan para darle vida y conciencia al personaje (Mohamed \& Mohd, 2015, pp. 115-116). El ejecutante animador se convierte en ilusionista de vida, concediéndole esa virtud vital a los personajes, los cuales adquieren una voluntad propia aparente, al darse la impresión de movimiento a través de la proyección. El títere rompe sus ataduras en la imagen proyectada en la animación, los hilos y cuerdas se vuelven invisibles ante el espectador y se construye el artificio detrás del gran telón animado.

La voluntad de la marioneta se ve expresada en un proceso que Geal (2018) denomina "doble animación” al presentarse objetos diegéticos animados, como también las imágenes técnicamente animadas (p. 81). El realizador de animación otorga vida a los personajes por medio de distintas técnicas de animación bidimensionales y tridimensionales, y en un momento posterior los personajes adquieren vida propia, seres que se independizan dentro de un mundo verosímil.

Un ejemplo de esta doble animación se puede constatar en películas como Toy Story (Lasseter, 1995), Toy Story 2 (Brannon, Unkrich \& Lasseter, 1999), Toy Story 3 (Unkrich, 2010) y Toy Story 4 (Cooley, 2019). La animación posee una capacidad ontológica e intertextual ${ }^{17}$

17 Se hace referencia a la intertextualidad en la relación narrativa que existe entre el "relato" del mundo "real" y la selección del "relato" de las realidades de los mundos 
que le permite crear estéticas ilusorias del movimiento y la vida por medio de un mundo de juguetes, aparentemente inanimados, que en la ausencia de espectador (humanos) se mueven con voluntad propia realizando el acto de "doble animación" (Geal, 2018, p. 71).

Así mismo, en la película clásica de Disney, Pinocchio (Ferguson et al., 1940), basada en el cuento de Carlo Collodi (2016 [1883]), se muestra un intertexto de cómo el acto creador del animador trasciende de la animación de una marioneta de madera a una marioneta libre de hilos, un "ser" racional dentro de su mundo, hasta el punto de renacer como un niño humano real. En dicho sentido, no se puede desligar la intención original que le da vigor al ser de madera, que es la intensa pasión del carpintero por tener un hijo de carne y hueso. En este caso, los anhelos y aspectos que enfocó Geppetto para llegar a tal prodigio se ven representados en una entidad externa que es el hada madrina, quien finalmente, al ver la preciosa elaboración, concede el deseo de la vida a este personaje.

En un sentido diferente, pero con unos índices narrativos similares en su trasfondo, el doctor Victor Frankenstein genera una suerte de hijo-creación por medio de su "monstruo", pero cuya intención subyacente no es tan pura si se quiere, sino que conlleva el combate contra la muerte en su haber. En dicho sentido, en este último ejemplo, se castiga la osadía de desafiar este estado, y lo que al principio parece ser una relación padre a hijo recién creada y llena de orgullo, rápidamente se convierte en una relación tortuosa de sentimientos llenos de ira y desprecio entre ambas partes.

Ahora bien, el viaje que hace la marioneta de madera Pinocchio para convertirse en un "ser" real contrasta con el de la criatura de Frankenstein (Shelley, 2015); la marioneta siente afecto por Geppetto, mientras que la criatura de Frankenstein rechaza a su padre hasta el punto de querer acabar con su vida, lo que muestra el viaje inverso que puede tomar la creación a favor o en contra de su creador. Esta cualidad doble también se ve reflejada en la máscara que proyecta el animador a través del sistema de visualización.

creados, lo que genera la diégesis narrativa. Partiendo de lo anterior se infiere que el animador interpreta la realidad a partir de conceptos que adquieren un nuevo significado en la animación. 
La máscara cumple una función doble al ser una máscara de la realidad del espectador, hilada a un contexto, representando al colectivo y a la máscara del animador como forma de representación.

El artificio de movimiento detrás de la máscara-pantalla permite que el personaje animado sea reconocido por la audiencia como un ser "real", gracias al gesto ${ }^{18}$ de "vida" que provee su ejecutante, el animador. El gesto es "un movimiento del rostro, de las manos o de otras partes del cuerpo, con el que se expresan afectos o se transmiten mensajes" (DRAE, 2019). No es solamente mover al personaje en un espacio, sino que es construir sentido y generar mensajes coherentes y cohesivos a través de su cuerpo, los cuales puedan ser apropiados por el público. Esto permite que se manifieste la cualidad doble de animación, ya que los personajes son concebidos como "reales", al lograr producir sentimientos y emociones con su cuerpo artificial en el cual el animador refleja su corporeidad.

Los personajes animados trascienden su carcasa de extrañeza, su disfraz, ya que el observador se siente identificado con el movimiento que estos cuerpos proveen (Mohamed \& Mohd, 2015, pp. 114-115). El movimiento corporal del personaje animado por medio del gesto de "vida" transmite mensajes cargados de contextos socioculturales, lo que genera una relación de identificación entre el público y el personaje. En el acto del gesto se encuentra el lenguaje y la cultura (Mohamed \& Mohd, 2015, p. 104). Debido a lo anterior, el gesto desempeña un papel importante en la animación, ya que establece las bases para una comunicación empática, el appeal. ${ }^{19}$

La artificialidad se ve sobrepasada por la experiencia kinestésica que cautiva al espectador (Mohamed \& Mohd, 2015, p. 114). Entre mayor es el sentido kinestésico de un actor o animador, mayor es la capacidad de representar a varios personajes y exhibir matices y gestos orgánicos (Giesen \& Khan, 2018, p. 36). La transición del títere como objeto inerte hacia el personaje animado es gracias al animador en cuanto ejecutante que dota del gesto de "vida" a lo inanimado.

18 En el marco del presente trabajo, se concibe el gesto desde la personificación y caracterización de los personajes, que difiere de la animación abstracta o experimental.

19 El appeal es uno de los doce principios de la animación planteados por Frank Thomas y Ollie Johnston en su libro Illusion of Life (1981), y hace alusión al vínculo empático entre el espectador y el producto animado. 
El gesto de "vida" aporta a la cualidad doble de la animación, ya que permite exagerar la tensión entre el creador y la creación al poner de manifiesto la artificialidad, como también al generar el movimiento autónomo, este último producto de la desobediencia de los personajes, que les aporta vitalidad y autonomía (Herhuth, 2016, p. 14). El personaje animado se independiza de su creador (el animador), quien lo dotó de vida, para finalmente emerger en el mundo como un ser autónomo. El animador deja un rastro sobre su obra, el personaje-creado adherido a unos principios de movimiento que luego se trasladan a su segundo estado, el de personaje-controlado, quien gracias a este movimiento pasa a su último estado, personaje-vivo, siendo un reflejo de su creador, pero a la vez construyendo su propia identidad.

\section{Avatares, cruce de fronteras en la dación del anima}

Tomando en cuenta la transición que ha tenido el acto creador del ser humano durante la historia del fenómeno del movimiento, se establecen puntos en común entre los diferentes ejecutantes y sus respectivas creaciones.

El constructor-operador, el titiritero y el animador son ejecutantes que trasladan los conceptos e ideas de la realidad a universos regidos bajo sus propias leyes. El acto creador se manifiesta por medio de diferentes mecanismos y sistemas que permiten construir un lenguaje gestual capaz de convertir el momento inerte y despojado de vida en una fuerza de movimiento.

En un primer momento el autómata, el títere y el personaje animado se encuentran en un estado neutro, observadores pasivos de alma latente. Luego entran en un segundo estado de control, supeditados por sus ejecutantes, quienes proveen movimiento a los cuerpos inertes; de este modo, al alojar emociones e ideas del "mundo real" y de sus ejecutantes, estos cuerpos se convierten en vehículos para el alma y sobrepasan la barrera de la inercia. El tercer estado es el de liberación: los entes logran romper las ataduras de sus creadores y producir movimiento creíble ante los ojos del espectador.

El proceso anterior posee una vitalidad que permite la ilusión de vida y es la encarnación del alma sobre los cuerpos. Para comprender 
el funcionamiento del alma sobre estos cuerpos, se remite al término de avatar, del sánscrito avatâra, "descenso o encarnación de un Dios" (DRAE, 2019). De acuerdo con el Diccionario de la RAE (2019), el avatar es una reencarnación o transformación que, en el hinduismo, corresponde a la encarnación terrestre de una deidad. El Diccionario Cambridge (2019), por su parte, la define como una imagen que representa a los usuarios en los juegos en línea, las salas de chat, etcétera; es decir, una entidad virtual que el usuario puede mover por la pantalla.

El avatar personifica y representa la idea de vida y logra aportar al ente la cualidad de ser concebido "real". Los ejecutantes encarnan parte de su esencia en los cuerpos del autómata, el títere y el personaje animado, cada uno siendo un avatar en determinados mundos. El cuerpo estático del avatar adquiere la cualidad de vivo gracias al impulso vital que le brinda su ejecutante, de modo que el avatar pasa de ser un cuerpo vacío a un cuerpo habitado por el reflejo del alma de su creador. En un segundo estado, el avatar encarna en el personaje que le fue designado, de tal suerte que construye su identidad y expresa su alma, con lo cual se desprende de su creador y logra ser "real" ante la audiencia. De este modo, el "avatar encarnado" es un ser que asume su propia existencia a partir de la esencia de sus ejecutantes.

A su vez, el "avatar encarnado" adquiere su propia agencia, ${ }^{20}$ que le permite generar identidad, y por tanto ya no es un "ente" vacío sino que se incorpora en su propio mundo, y se convierte en un "ser" real cuando es reproducido en la máscara-pantalla y es visto por el observador (Figura 4). Añade Crafton (2013) que los personajes animados tienen agencia en el mundo que comparten con los espectadores; los animadores tienen agencia en el mundo que comparten con los personajes animados, y el público tiene agencia en ambos mundos (p. 71). Lo anterior también aplica tanto para el constructor, operador-autómata, como para el titiriterotítere, lo que crea relaciones de control y libertad entre el ejecutante y el "avatar encarnado".

20 El término de agency es descrito por Crafton (2013) como la capacidad de lograr que ocurran eventos, controlar a otros seres, reaccionar a los acontecimientos de manera sensible o, simplemente, afirmar una autonomía. 


\section{Imagen 4}

Proceso iterativo de transformación del cuerpo estacionario "ente", al "ser" real y vivo
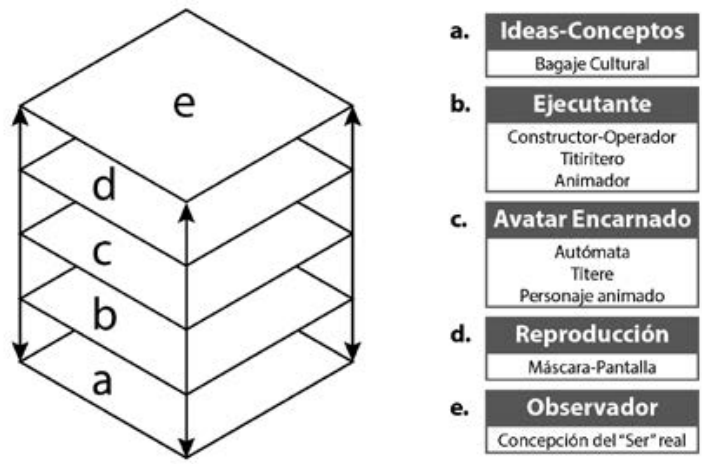

Fuente: Elaboración nuestra.

Los caminos del autómata, del titiritero y el animador se encuentran probablemente en la ruta hacia la inteligencia artificial, siendo un claro ejemplo lo que ocurre en los videojuegos. En ellos, el jugador actúa a manera de titiritero "gobernando" electrónicamente a un personaje que se dirige según sus designios; la consola actúa como autómata "respondiendo" a las acciones del intruso de manera automática, y los ejercicios en sí mismos de ambos están siendo visualizados a manera de animaciones proyectadas.

Bajo esta perspectiva, el animador ya no es solamente un creador, sino que se convierte en actor que moviliza y agencia dinámicas culturales y sociales (Thomas y Buch, 2013, pp. 101-102) sobre los procesos que transforman la práctica de animar en un sistema tecnológico (que involucra sistemas técnicos artesanales y tecnológicos), similar a lo planteado por Quintanilla (2000, pp. 2-3). Es decir, el proceso de animar se entiende como un escenario de interacción poiética, en el cual se intervienen una serie de objetos en sus atributos formales (posición, escala, textura, color, lógica física, etcétera) por intermedio de distintos grupos de herramientas técnicas (sistemas, mecanismos, estructuras de implementación) con la intención de "construir" las unidades estáticas que posteriormente conforman el artefacto audiovisual animado, sea cual sea (Patrick, citado por Traslaviña, Durán y Martínez, 2013). 
Este intercambio de formas de representación evidencia un escalón más en la búsqueda de la creación del reflejo, verbigracia, con el desarrollo del holograma, figura que la ciencia ficción ha propuesto en filmes como la saga Star Wars de George Lucas, desde 1977, o la película I, Robot (Proyas, 2004), entre otros, pero que actualmente empieza a configurarse como propuesta real en ejemplos como los de Hatsune Miku, cantante virtual japonesa que ya recauda enormes ganancias, a pesar de ser solo un personaje de animación en 3D.

El avance tecnológico permite a los ejecutantes trasladar sus creaciones, los "avatares encarnados", a espacios donde el acto creador encuentra su vitalidad por medio de diferentes artificios que sumergen al espectador en realidades que modifican su percepción del mundo. El autómata, el títere y el personaje animado se convierten en vestigios para las nuevas tecnologías como la estereoscopía, la holografía, la realidad aumentada (AR), la realidad virtual (VR), la captura de movimiento, el sistema image-metrics, la inteligencia artificial (AI), los videojuegos, la robótica, entre otros sistemas tecnológicos que se salen del marco del presente trabajo; sin embargo, son una visión del ansia del ser humano por crear vida y trascender. Estos medios conceden al "avatar encarnado" la capacidad de interactuar con el espectador dentro del mundo real y el mundo virtual, e incluso el mismo espectador se convierte en el "avatar encarnado" al proyectar su corporeidad en los diferentes universos creados.

El recorrido que el ser humano ha trasegado en la búsqueda de la comprensión del movimiento y las formas de autorreconocimiento lo lleva constantemente a cruzar los límites de su propia existencia y seguirá permitiéndole explotar los conocimientos que adquiere del mundo que lo rodea

\section{Conclusiones}

La idea de movimiento se consolida de diversas maneras en la construcción contemporánea del concepto de animación, la dación de la vida. En primera instancia con los autómatas, cuya forma representable se enmarca en la ejecución mecánica por medio de rangos parametrizados de respuestas; en segunda instancia, con los títeres y marionetas como una proyección plástica y espontánea de la 
participación del ejecutante sobre mecanismos y objetos inanimados, y por último, el personaje animado a través de secuencias de imágenes que explotan las posibilidades infinitas de representación de la forma al jugar con la física del mundo. Estas maneras de representar o ejecutar el movimiento buscan una respuesta emocional de los espectadores que genere una brecha en la cotidianidad de la realidad natural y construya a su vez un espacio momentáneo de alteridad de la realidad.

Al abordar el movimiento desde el autómata al personaje animado, partiendo de la pregunta enigmática por el anima, se presentan diferentes relaciones de control-libertad y dependenciaindependencia entre los ejecutantes y sus creaciones. Esto permite que el "alma móvil" se refleje en el cuerpo, en el "avatar encarnado", como una entidad con agencia propia capaz de articular los contenidos y las emociones en diferentes circunstancias espaciotemporales de ejecutantes y espectadores, lo que lo convierte en un ser "real" a través de la máscara-pantalla.

El grado de aceptabilidad del ser "real" y vivo se construye a partir del proceso iterativo de realimentación entre el ejecutante, el avatar encarnado y la audiencia. Este proceso de interacción se ve reflejado en el avance tecnológico que desdibuja las fronteras entre lo inmóvil y lo móvil-vivo, y recrea un nuevo escenario de convivencia entre ejecutantes y "avatares encarnados", que recorren un camino hacia nuevas realidades.

La evolución tecnológica no solo exige un refinamiento de los procesos mecánicos de apropiación de los fenómenos naturales o de los sistemas de proyección y representación cinética, sino que, en su afán de entender de manera más profunda estos procesos, involucra a las computadoras en medio de la conciliación de las tres formas ya mencionadas anteriormente. Esta relación se podría llegar a definir a partir del concepto propuesto por Bueno y Peirano (2009, pp. 323361) de los "autómatas digitales", en un sentido en el que si bien lograr un desarrollo computarizado que piense por sí mismo no es factible aún, se han logrado avances en el proceso de imitación y capacidades de interpretación que pueden engañar el sentido humano en su naturaleza siniestra. ${ }^{21}$

21 Es el caso de las computadoras Deep Blue o Watson, que si bien en su propia integridad no 
Esto lleva a asumir entonces la construcción de entidades que representen el movimiento, un nuevo tipo de ejecutantes que, abstrayendo los conocimientos derivados de sus antecesores, llevan a un espacio diferente sus creaciones. El animador se apropia de las potencialidades de las computadoras, que le permiten representar el movimiento en imágenes como extensión de su capacidad creativa. Aprovecha las posibilidades que la tecnología ofrece en la construcción del ser digital para desarrollar nuevos mecanismos digitales, esqueletos virtuales, y definir las limitantes plásticas que se pueden aprovechar en la automatización de comportamientos y expresiones que se identifiquen con el ser humano.

En el movimiento como principio vital, ya sea por medio de un acto de la voluntad divina o con el proceso calculado de manipular dispositivos, el acto de animar requiere de una fuente de energía. Por tanto, el "autómata digital" es una caja de Pandora autoconformada, el "ser" que lleva dentro de sí todo el ingenio de su creador y cubre por completo a su ejecutante, siendo este último una versión moderna del que lograba su objetivo por medio de una labor mecánica o del cabalista del Golem, que con la magia y la palabra de vida posee control y anima; ahora reemplazado o actualizado en la forma del animador que, con la ayuda de la voz de un actor, le da vida a un vaquero de juguete (Lasseter, 1995) I

\section{Referencias}

Aldiss, B. (1969). Supertoys Last All Summer Long and Other Stories of Future Time. St. Martin's Press.

Arce, R., Sánchez, C., y Velásquez, Ó. (2013). La animación en Colombia hasta finales de los años 80. Universidad de Bogotá Jorge Tadeo Lozano. https://bit.ly/2yGOogL

Asimov, I. (1942). Runaround. Astounding Science Fiction.

Asimov, I. (1976). The Bicentennial Man. En The Complete Stories (vol. 2). Broadway Books.

responden intuitivamente -de ahí la duda del campeón Kaspárov-, han sido programadas con tal cantidad de información que sus respuestas son tan amplias y su capacidad de procesamiento tan alta que logran encontrar respuestas viables a situaciones inmediatas. 
Asimov, I. (1985). Robots and Empire. Doubleday.

Asimov, I. (2001 [1951]). Satisfaction Guaranteed. En The Complete Stories (vol. 1). Broadway Books.

Bird, B. (Director). (1999). The Iron Giant [cinta cinematográfica]. Warner Bros.

Brannon, A., Unkrich, L. \& Lasseter, J. (Directores). (1999). Toy Story 2 [cinta cinematográfica]. Walt Disney Pictures; Pixar Animation Studios.

Brin, D. (2002). Kiln People. Tor Books, Macmillan Publishers.

Buchan, S., Surman, D., \& Ward, P. (2006). Animated Worlds. John Libbey Publishing.

Bueno Gómez-Tejedor, S., \& Peirano, M. (2009). El rival de Prometeo: Vidas de autómatas ilustres. Gráficas Zamart.

Cambridge Dictionary. (2019). Avatar. Dictionary.cambridge.org. https://bit. $1 y / 38 \mathrm{BS} 7 \mathrm{Kg}$

Cameron, J. (Director). (2009). Avatar [cinta cinematográfica]. 20th Century Fox, Lightstorm Entertainment, Giant Studios Inc.

Čapek, K. (2017 [1920]). R.U.R. Robots Universales Rossum: obra en tres actos y un epílogo. Libros Mablaz.

Carpenter, N. (2012). Diablo III: Reaper of Souls [videojuego]. Blizzard Entertainment.

Chinchilla Sánchez, K. (2001). De la cábala al golem mágico. Revista de Filología y Lingüística de La Universidad de Costa Rica, 27(2), 7-22. https://doi.org/10.15517/rfl.v27i2.21025

Cholodenko, A. (2007). (The) Death (of) the Animator, or: The Felicity of Felix - Part II: A Difficulty in the Path of Animation Studies. Animation Studies, 2(Part II), 9-16. https://bit.ly/2LciQ4T

Cholodenko, A. (2009). Animation (Theory) as the Poematic: A Reply to the Cognitivists. Animation Studies, 4, 1-16. https://bit.ly/3bko2yg

Cholodenko, A. (2016, octubre 11). The Expanding Universe of Animation (Studies). Animation Studies Online Journal, 11. https://bit.ly/3f9kvpt

Chung, P., Jones, A., Kawajiri, Y., Koike, T., Maeda, M., Morimoto, 
K., Watanabe, S. (Directores). (2003). The Animatrix [cinta cinematográfica]. Madhouse, DNA, Silver Pictures, Square USA, Studio $4^{\circ} \mathrm{C}$, Warner Bros. [Animación].

Collodi, C. (2016 [1883]). Las aventuras de Pinocho. Nostra Ediciones.

Cooley, J. (Director). (2019). Toy Story 4 [cinta cinematográfica]. Pixar Animation Studios. Distributed by Walt Disney Pictures.

Crafton, D. (2013). Shadow of a mouse: Performance, belief, and worldmaking in animation. Universtity of California Press.

Davis, D. (Director). (1981). Clash of the Titans [cinta cinematográfica]. Metro-Goldwyn-Mayer.

De Chomon, S. (Director). (1908). El hotel eléctrico [cinta cinematográfica]. Pathé Frères.

De l'Isle-Adam, A. V. (1998 [1886]). La eva futura. Valdemar.

De la Mettrie, J. O. (1748). L'Homme Machine. Elie Luzac \& Fils.

Diccionario de la Real Academia Española, DRAE. (2019). Avatar. Rae.es. https://dle.rae.es/?id=4X6SYjl

Diccionario de la Real Academia Española, DRAE. (2019). Gesto. Rae.es. https://dle.rae.es/?id=JARGBj1

Dick, P. K. (1968). Do Androids Dream of Electric Sheep? Doubleday.

Ferguson, N., Hee, T., Jackson, W., Kinney, J., Luske, H., Roberts, B. \& Sharpsteen, B. (Directores). (1940). Pinocchio [cinta cinematográfica]. Walt Disney Productions.

Geal, R. (2018). Animated Images and Animated Objects in the Toy Story Franchise: Reflexively and Intertextually Transgressive Mimesis. Animation, 13(1), 69-84. https://doi.org/10.1177/1746847717752588

Giesen, R., \& Khan, A. (2018). Acting and Character Animation: The Art of Animated Films, Acting and Visualizing. CRC Press.

Herhuth, E. (2016). The Politics of Animation and the Animation of Politics. Animation, 11(1), 4-22. https://doi.org/10.1177/1746847715624581

Hoffmann, E. T. A. (1921 [1816]). Der Sandman. Nicolaische Verlagsbuchhandlung. 
Hooks, E. (2017). Craft Notes for Animators: A Perspective on a 21st Century Career. Taylor \& Francis.

Jonze, S. (Director). (2013). Her [cinta cinematográfica]. Annapurna Pictures.

Lang, F. (Director). (1927). Metrópolis [cinta cinematográfica]. U. F. A.

Lasseter, J. (director). (1995). Toy Story [cinta cinematográfica]. Walt Disney Pictures; Pixar Animation Studios.

Lorenzo Hernández, M. (2013). Morel_Moreau_Morella: The Metamorphoses of Adolfo Bioy Casares' Invention in a (Re) Animating Universe. Animation, 8(2), 185-202. https://doi. org/10.1177/1746847713485535

Maeda, M. (Director). (2003). The Second Renaissance Part I EF II [cinta cinematográfica]. Studio $4^{\circ} \mathrm{C}$, Warner Bros.

Meyrink, G. (1995). El Golem. Tusquets.

Minsky, M. (2006). The Emotion Machine: Commonsense Thinking, Artificial Intelligence, and the Future of the Human Mind. Simon \& Schuster.

Mohamed, F. N., \& Mohd Nor, N. L. (2015). Puppet Animation Films and Gesture Aesthetics. Animation, 10(2), 102-118. https://doi. org/10.1177/1746847715587425

Montoya Santamaría, J. W. (2011). Tecnociencia y racionalidad en el mundo contemporáneo. Trilogía, (4), 69-76. https://doi. org/10.22430/21457778.140

Mori, M. (1970). The Uncanny Valley. Energy, 7(4), 33-35. https://bit. ly/2zqM10c

Morimoto, K. (Director). (1995). Magnetic Rose [cinta cinematográfica]. Studio $4^{\circ} \mathrm{C}$.

Nomura, T., \& Nozue, T. (Directores). (2005). Final Fantasy VII: Advent Children [cinta cinematográfica]. Visual Works, Square Enix, Square USA.

Oshii, M. (Director). (1995). Ghost in the Shell [cinta cinematográfica]. Bandai Visual Company, Kodansha, Manga Video, Production I. G.

Páramo, G., James, A. J., y Jiménez, D. A. (2004). Chamanismo: el otro 
hombre, la otra selva, el otro mundo: entrevistas a especialistas sobre la magia y la filosofía amerindia (Vol. 1). Instituto Colombiano de Antropología e Historia.

Pikkov, Ü. (2010). Animasophy: Theoretical Writings on the Animated Film. Estonian Academy of Arts. https://bit.ly/2zsDvis

Proyas, A. (Director). (2004). I, Robot [cinta cinematográfica]. 20th Century Fox.

Quintanilla, M. Á. (2000). Técnica y cultura. Teorema, 17(3), 1-16. https:// www.oei.es/historico/salactsi/teorema03.htm

Raynaud, G., González de Mendoza, J. M. y Asturias, M. Á. (2004). El Libro del Consejo (Popol Vuh) (5..$^{a}$ ed.). Universidad Nacional Autónoma de México.

Rucker, R. (1988). Wetware. Avon Books.

Sanders, R. (Director). (2017). Ghost in the Shell [cinta cinematográfica]. DreamWorks SKG, Grosvenor Park, Seaside Entertainment.

Sanín Santamaría, J. D. (2009). Estéticas del consumo: configuraciones de la cultura material. Revista Colombiana de Antropología, 45(1), 225-229. https://bit.ly/2WkQKep

Scorsese, M. (Director). (2011). Hugo [cinta cinematográfica]. GK Films, Infinitum Nihil, Paramount Pictures.

Scott, R. (Director). (1982). Blade Runner [cinta cinematográfica]. Warner Bros, Ladd Company, Shaw Brothers.

Shelley, M. (2015 [1818]). Frankenstein or, The modern Prometheus. Oxford University Pres

Sierra Monsalve, S. H. (2015). Acciones corporales dinámicas. Metodología del movimiento físico para intérpretes escénicos inspirada en el Principio de Alteración del Equilibrio (Tesis doctoral). Universidad Autónoma de Barcelona. https://bit.ly/2YPpiXx

Solomon, C., (Ed.). (1987). The art of animated image: An Anthology. The American Film Institute.

Spielberg, S. (Director). (2001). A. I. Artificial Intelligence [cinta cinematográfica]. Warner Bros, DreamWorks SKG, Amblin Entertainment, Stanley Kubrick Production. 
Taddei, M. (2010). Los robots de Leonardo Da Vinci. La mecánica y los nuevos autómatas encontrados en los códices. Tikal.

Thibault, M. (2016). Lotman and play: For a theory of playfulness based on semiotics of culture. Sign Systems Studies, 44(3), 295-325. http://dx.doi. org/10.12697/SSS.2016.44.3.01

Thomas, F., \& Johnston, O. (1981). The illusion of life: Disney animation. Disney Editions.

Thomas, H. y Buch, A. (2013). Actos, actores y artefactos. Sociología de la tecnología. Editorial Universidad Nacional de Quilmes.

Traslaviña, C., Durán, M. y Martínez, G. A. (2013). Perpetuum Mobile I Espacio y tiempo. Catálogo de Obras Artísticas. Pontificia Universidad Javeriana. http://catalogodeobras.javeriana.edu.co/catalogodeobras/ items/show $/ 2$

Trousdale, G. y Wise, K. (Directores). (1991). La bella y la bestia [cinta cinematográfica]. Walt Disney Pictures, Silver Screen Partners IV, Walt Disney Feature Animation.

Unkrich, L. (director). (2010). Toy Story 3 [cinta cinematográfica]. Walt Disney Pictures, Pixar Animation Studios.

Wagensberg, J. (2004). La rebelión de las formas: O cómo perseverar cuando la incertidumbre aprieta. Tusquets.

Zemeckis, R. (Director). (2007). Beowulf [cinta cinematográfica]. Warner Bros. Pictures, Paramount Pictures, ImageMovers, Shangri-La Entertainment. 